\title{
CHECK-LIST DE CRUSTÁCEOS CAPTURADOS POR ARMADILHA LUMINOSA EM ÁREA RECIFAL NO LITORAL SUL DE PERNAMBUCO
}

\author{
Negromonte, A.O. ${ }^{1,}$; Duda, M.L.F. ${ }^{1}$; Esteves, P.H. ${ }^{\text {; }}$, Santos-Junior, C.A.L. '; Falcão-Pinto, R.M. ${ }^{\text {; }}$ \\ Silva, I.F. ${ }^{1}$; Melo-Andrade, R. ${ }^{1}$; Ferreira, B.P. ${ }^{1}$ \& Souza-Filho, J.F. ${ }^{1}$
}

${ }^{1}$ Laboratório de Carcinologia, Museu de Oceanografia Professor Dr. Petrônio Alves Coelho da Universidade Federal de Pernambuco (UFPE). Av. Arquitetura, s/n, Cidade Universitária, Recife - PE.

*Autor correspondente: aurinegromonte@gmail.com

\begin{abstract}
A metodologia de coleta usando de armadilhas luminosas tem se mostrado muito eficiente desde o início de seu uso na Grande Barreira de Corais, mostrado efeito positivo na atração e captura de peixes e outros invertebrados zooplanctônicos, nectônicos e bentônicos. Por sua vez, os crustáceos planctônicos e bêntonicos são atraídos por essas armadilhas, pois a luz é o fator mais importante que influencia crustáceos na migração vertical diária. As coletas foram realizadas mensalmente no período de dezembro/2010 até abril/2016 em diversas fases da lua, através da técnica de captura por armadilhas de luz (CARE®) "Capture by Artificial Reef Eco-friendly", desenvolvida pela empresa francesa ECOCEAN). Foram marcados três pontos no complexo recifal da praia de Tamandaré e inserida na Área de Proteção Ambiental Costa dos Corais. As armadilhas foram instaladas por três dias consecutivos no fim do pôr-do-sol nas diferentes fases da lua (cheia, minguante, nova e crescente). As armadilhas foram fixadas de maneira transversal no canal de acesso navegacional da Baía de Tamandaré, numa profundidade de 8 a 12 metros, permanecendo aproximadamente $12 \mathrm{~h}$ em subsuperfície $1 \mathrm{~m}$ de profundidade, sendo assim retiradas ao amanhecer. Os crustáceos foram separados dos demais invertebrados e separados em grandes grupos. Foram encontrados indivíduos adultos, juvenis dos seguintes grupos: dentre os peracarida Mysida, Amphipoda, Isopoda e Cumacea; no grupo dos Decapoda Portunidae, Paleamonidae, Sergestidae, Luciferidae, Palinuridae, Scylaridae, Axiidae, Galatheidae e as formas larvais de Brachyura (Zoea e Megalopa); além de representantes dos grupos Stomatopoda, Copepoda e Ostracoda. Com esses resultados, torna-se compreensível quais grupos de crustáceos, de importância econômica e ecológica, que são atraídos por armadilhas luminosas realizando migração vertical em Tamandaré, Pernambuco.
\end{abstract}

Palavras-chave: armadilhas de luz, unidade de conservação, invertebrados. 